FACULDADES INTEGRADAS DE FERNANDÓPOLIS (FIFE)

FUNDAÇÃO EDUCACIONAL DE FERNANDÓPOLIS (FEF)

Arthur Brito Padúla

Brenda Inácio

ÉTICA PROFISSIONAL CONTABIL E A CONDUTA EXIGIDA DO CONTADOR PELO CÓDIGO DE ÉTICA PROFISSIONAL 
Arthur Brito Padúla

Brenda Inácio

\section{ÉTICA PROFISSIONAL CONTABIL E A CONDUTA DO CONTADOR EXIGIDA PELO CÓDIGO DE ÉTICA PROFISSIONAL}

Trabalho apresentado ao curso de Ciências Contábeis das Faculdades Integradas de Fernandópolis, como obtenção de nota parcial para a disciplina de Trabalho de Conclusão de Curso I sob a orientação da professora Me. Elaine Doro Mardegan Costa.

Fernandópolis-SP

2019 


\title{
ÉTICA PROFISSIONAL CONTABIL E A CONDUTA DO CONTADOR EXIGIDA PELO CÓDIGO DE ÉTICA PROFISSIONAL
}

\author{
Arthur Brito PADÚLA ${ }^{1}$ \\ Brenda INACIO ${ }^{2}$ \\ Orientadora: Me. Elaine Doro Mardegan Costa ${ }^{3}$
}

\begin{abstract}
RESUMO
Ética é ciência normativa da retidão dos atos humanos, de acordo com princípios racionais da Filosofia. Já ética profissional são princípios e valores morais propostos para nortear a conduta em âmbito profissional. Objetiva-se apresentar a importância da ética profissional por meio da análise do código ética contábil e mostrar sua influência na conduta e exercício do contador. O estudo ocorreu por meio da pesquisa descritiva bibliográfica, sendo realizada por meio de leitura de livros e artigos disponíveis em dados eletrônicos. Com o trabalho, pode-se notar que as virtudes morais é prática fundamental na conduta do contador, pois é exigência na execução da atividade profissional contábil. Por isso, é importante agir conforme prescreve o código de ética profissional: com apreço, integridade, honestidade, franqueza, responsabilidade, sinceridade e zelo. Os contadores devem restringir-se a ganhos ou vantagens pessoais pelo uso de informações contábeis e financeiras confidenciais e evitar oportunidade intencional de enganar e manipular informações de seus clientes em proveito próprio. Além disso, precisa ser verdadeiro ao oferecer serviços contábeis, bem como, ser preciso ao fornecer avaliação da saúde financeira aos usuários e interessados pela contabilidade. Ressalta-se a importância do Código de Ética Profissional para garantir conduta ética e consistente de todos os profissionais; porém, na ausência, cabe denuncia ao Conselho Federal de Contabilidade, para proceder com aplicações de sanções éticas descritas no código. Portanto, a conduta ética exigida ao contador é norteada pelo Código de Ética que, regulamenta e orienta o trabalho, mas formaliza as penalidades na falta de seu uso.
\end{abstract}

PALAVRAS-CHAVE: Ética. Ética Profissional. Código de Ética Profissional. Contador. Contabilidade.

\begin{abstract}
Ethik ist die normative Wissenschaft von der Gerechtigkeit menschlicher Handlungen nach rationalen Prinzipien der Philosophie. Berufsethik sind Grundsätze und moralische Werte, die vorgeschlagen werden, um das berufliche Verhalten zu leiten. Ziel ist es, die Bedeutung der Berufsethik durch die Analyse des Ethikkodex für die Rechnungslegung aufzuzeigen und seinen Einfluss auf das Verhalten und die Ausübung des Buchhalters aufzuzeigen. Die Studie erfolgte durch deskriptive
\end{abstract}


bibliografische Recherchen, bei denen Bücher und Artikel gelesen wurden, die in elektronischen Daten verfügbar waren. Bei der Arbeit kann festgestellt werden, dass die moralischen Tugenden eine grundlegende Praxis im Verhalten des Buchhalters sind, da sie eine Voraussetzung für die Ausübung seiner beruflichen Tätigkeit als Buchhalter sind. Es ist daher wichtig, die berufsethischen Grundsätze einzuhalten: mit Wertschätzung, Integrität, Ehrlichkeit, Offenheit, Verantwortung, Aufrichtigkeit und Eifer. Buchhalter sollten sich durch die Verwendung vertraulicher Buchhaltungs- und Finanzinformationen auf den persönlichen Gewinn oder Vorteil beschränken und die absichtliche Möglichkeit vermeiden, Kundendaten zu ihrem Vorteil irrezuführen und zu manipulieren. Darüber hinaus muss es zutreffen, dass Buchhaltungsdienstleistungen erbracht werden, und es muss den Benutzern und den an der Buchhaltung Interessierten eine genaue Bewertung des finanziellen Zustands zur Verfügung gestellt werden. Betont, wie wichtig der Berufsethikkodex ist, um ein ethisches und konsistentes Verhalten aller Fachkräfte zu gewährleisten; Ist dies nicht der Fall, ist der Bundesrechnungslegungsrat dafür verantwortlich, die im Kodex beschriebenen ethischen Sanktionen anzuwenden. Daher richtet sich das vom Buchhalter geforderte ethische Verhalten nach dem Ethikkodex, der die Arbeit regelt und leitet, aber die Strafen für die Nichtverwendung festlegt.

SCHLÜSSELWÖRTER: Ethik. Berufsethik. Kodex der Berufsethik. Buchhalter Buchhaltung

\section{INTRODUÇÃO}

A ética faz parte, ou melhor, deve fazer parte do campo pessoal e, por extensão, do profissional, pois enfatizam princípios e valores morais como sinceridade, boa fé e profissionalismo.

No caso, dos contadores, nota-se que a profissão de contabilidade a fim de nortear e direcionar a conduta de seus profissionais, sejam contadores ou técnicos em contabilidade, possuem seu próprio Código de Ética Profissional, o qual é instituído pelo Conselho Federal de Contabilidade, com a intenção de efetivar regras de conduta que abrangem diferentes virtudes básicas como: Integridade, objetividade, confidencialidade, competência, confidencialidade, bem como direitos e deveres a serem observados no cumprimento de suas funções. Tal código também evidencia as punições, quando o comportamento exigido ao profissional não se adeque as exigências para profissão. (ARANHA; MARTINS, 2010).

A natureza do trabalho realizado por contadores exige a prática da ética. A contabilidade se preocupa com a verdade na forma de descrições numéricas fiéis 
das atividades comerciais, pois princípios éticos que orientam a profissão para que possa preconizar o fornecimento de informações precisas e imparciais. (CFC, 2015).

A ética na contabilidade evidencia diretriz e princípios, que são propostos a partir de padrões específicos de conduta, os quais são estabelecidos como regras e normas exigidas para o profissional da contabilidade. (CFC, 2015).

Ressalta-se que o profissional de contabilidade ao identificar ameaças em relação a sua conduta, deve comunicar o Conselho Federal de Contabilidade (CFC), já que é um órgão superior no caso da profissão contábil. Uma vez que este órgão ao propor os princípios éticos, por meio do Código de Ética Profissional, busca eliminar ou reduzir ameaças em nível aceitável, para que o cumprimento dos princípios e legislações contábeis, também não sejam postos em risco. (MELO, 2019).

Assim, o presente estudo tem o objetivo de apresentar a importância da ética profissional por meio da análise do código ética contábil e mostrar sua influência na conduta e exercício do contador.

A realização do referido trabalho ocorreu por meio das aplicações da pesquisa descritiva bibliográfica, sendo a coleta de dados realizada, por meio de leitura de livros e pesquisas em artigos disponíveis em banco de dados eletrônicos.

\section{REVISÃO DE LITERATURA}

\section{1 Ética: fundamentos e conceitos}

A ética pode ser definida como ciência do comportamento moral, sendo determinado por meio de análise de todos os membros pertencentes a uma sociedade, os quais devem agir em comum acordo. Deve-se notar que a ética não é coercitiva, pois, como sanções legais não são impostas ao indivíduo, já que se trata de processo de conscientização, ou melhor, de regulamentação que é promovida por meio de normas estabelecidas coletivamente para todos. (ALVES et al., 2016).

Diante o exposto, pode-se relatar que a ética se torna predominante, pois a aplicação prática pelo homem é determinante também do seu agir em grupos sociais, os quais favorecem as transformações sociais. Neste caso, "o bem passa a ser uma decorrência do móvel da conduta, ou ainda, o que se consegue através de seguir-se tal ou qual direção". (SÁ, 2000, p. 26). 
De forma simplificada, define-se a ética como ramo de filosofia que lida com o que é moralmente bom ou mal certo ou errado. Pode-se dizer, também, que a etimologia dos termos ética e filosofia moral são sinônimas, pois ambas significam costumes. Nesse sentido pode-se dizer que ética e moral são complementos uma da outra.

"Em uso popular, embora apresente diferentes significados, um deles sempre mencionado é que ética diz respeito aos princípios de conduta que norteiam um individuo ou grupo de indivíduos". (LISBOA, 1997, p. 23).

De acordo com Cortina e Martinéz (2015), a ética pode ser compreendida por meio de várias teorias, cujos ramos do saber acerca da ética, encontram-se divididos em: ética normativa e ética aplicada.

- ÉTICA NORMATIVA: enfatiza oque deve ser considerado bom ou ruim para uma pessoa. Dedica-se à elaboração e posteriormente à formação de normas sociais, e exclui o monitoramento e / ou cumprimento das mesmas. É possível classificar os atos humanos como corretos e incorretos, sem levar em conta preconceitos, pois um comportamento ou ação humana é adequado ou inadequado, dependendo de como agirá.

- ÉTICA APLICADA: campos atuais de filosofia contemporânea, sendo proposta reflexão sobre o fundamento das normas. Ética aplicada refere-se a diferentes áreas como: bioética; ética ambiental; engenharia ética; ética profissional; ética politica, e varias outras concepções nessas áreas, a ética aplicada lida com problemas éticos cotidianos, pois trata do estudo de questões morais e de suas controvérsias referidos ao campo em especificidade.

Só propor estudo sobre a ética profissional, nota-se e que podem ser incluídos os códigos de ética para regular uma atividade profissional. Estes por sua vez são norteados pela deontologia que deriva do termo grego deontos e significa obrigatório. Está questão filosófica faz parte do que é conhecido como ética normativa e apresenta uma série de princípios e regras que se tornam obrigatória, pois adquirem consenso da maioria das pessoas envolvidas. 
Para Valls (1993, p. 7 apud ARANHA; MARTINS, 2010, p. 298.) "a ética é daquelas coisas que todo mundo sabe o que são, mas que não são fáceis de explicar, quando alguém pergunta".

Neste contexto, pode-se em uma visão da ética aplicada as profissões, entender que a ética representa sim, os valores e os princípios que orientam a conduta humana em sociedade, pois se relaciona ao caráter individual.

\section{2 Ética Profissional}

Ética profissional é conduta muito valorizada no mercado de trabalho, pois é um conjunto de normas e regras que visam à melhoria no ambiente de trabalho, pois envolve a consciência profissional e, por isso, representa os padrões de comportamentos esperados para a profissão. Por isso, ao ser aplicado ao contador, tem-se o propósito de desenvolver a consciência da importância de agir com valores morais na condução das relações profissionais.

Acerca deste posicionamento, Lisboa (1997, p. 11) deixa bem claro a importância da ética nas profissões:

Não há sociedade que progrida com firmeza por muito tempo, que se mantenha politicamente consistente, que ofereça bem estar social a seus membros, nem profissão que se imponha pelo produto de seu trabalho que se faça reconhecer por seus próprios méritos, sem que esteja a Ética a servir de cimento a fortalecer sua estrutura, de amarras a suportar as tempestades, de alicerce a suportar o crescimento e de raízes e seiva para garantir a sobrevivência dessa sociedade ou dessa profissão. Sem Ética, a sociedade não se estrutura de forma permanente; e uma profissão também não (MARTINS, 2010, p.12).

No que se refere à profissão de contador, pode-se destacar que a ética deve ser exercida tanto no setor público quanto no privado, uma vez que é uma profissão liberal, com amplo escopo de aplicação, mas, apesar dessa liberdade, não se pode ignorar a responsabilidade social; já que as ações do contador devem estar em consonância com as normas e / ou princípios, sem deixar de observar os princípios legais (LUSTOSA et al., 2015).

Nota-se que atualmente encontra-se na sociedade pessoas que não atendem aos padrões mínimos de convivência pacífica, sendo evidente a falta de valores, que por sua vez no desempenho profissional, acaba por agir de forma a afetar a imagem 
da classe profissional. Assim, é impossível para os diferentes profissionais aplicar padrões éticos ao realizar qualquer trabalho independente da profissão ou do setor em que estão trabalhando. (LUSTOSA et al., 2015).

A profissão contábil é indispensável para o Estado, pois, por meio da quantificação de fatos econômicos, fornece ferramentas e informações necessárias para determinar e analisar variáveis dos diferentes atores econômicos que afetam as finanças públicas ou públicas. Por esse motivo, a importância da contabilidade na relação Estado-economia não deve ser ignorada; é aí que o papel do Contador passa a ter maior relevância, devido à grande responsabilidade social envolvida no desenvolvimento da profissão contábil, juntamente com a Ética profissional (DANTAS et al., 2014).

Não é possível ignorar a responsabilidade que os Contadores têm na situação que o país vivência. Atualmente em termos de sonegação de impostos, escândalos e corrupção porque é um dos problemas fiscais mais delicados, nos quais a ética profissional atesta e da fé pública as informações financeiras de empresas públicas e privadas que são fornecidas pelos contadores. Para o Contador, é uma convocação especial agir em conformidade com o Código de Ética Profissional, uma vez que são depositários os melhores empenhos para afirmar uma conduta ética (FREITAS et al., 2017).

Com o exposto, destaca-se que a prática profissional do Contador deve sempre estar vinculada aos princípios éticos da profissão, independentemente do tipo de trabalho que se desenvolve, ou seja, no setor privado, deve ser garantidor do Estado, em matéria tributária refletir as informações de forma imparcial e verdadeira, em conformidade com todas as obrigações fiscais; Se o caso for do setor público, deve realizar seu trabalho com toda a ética profissional, a fim de facilitar a execução eficiente dos recursos e o cumprimento dos objetivos do Estado, principalmente, sociais (MORAES et al., 2016).

O contador é assistido por uma responsabilidade social de alto impacto, que pode cumprir apenas se operar de acordo com a lei e sempre com base na ética profissional sólida e inabalável. Seu campo de ação é bastante amplo, já que profissional tem acesso a informações fiscais, econômicas e financeiras que, quando manipuladas ou traduzidas de má-fé, podem beneficiar alguns e afetar muitos outros, como: investidores, funcionários da organização, entidades tributárias e até a sociedade em geral. Nota-se que o contador tem compromisso com o Estado, mas 
também com a própria sociedade, Afinal a saúde do tesouro depende em grande parte de procedimento correto e ético das dos profissionais da contabilidade (ANTONOVZ et al., 2016).

É poder das Associações Profissionais estabelecer padrões éticos que, adaptados às realidades de cada profissão, ajudem, por um lado, a definir claramente a conduta ética desejável de seus profissionais e, por outro lado, a evitar comportamentos indesejados que resultem em demérito (ALVEST et al., 2016).

Assim os códigos de ética são as normas nas quais as idéias centrais do comportamento corporativo são expressas, pois se destina servir como padrão de conduta para os profissionais de Contabilidade, que, como profissão de treinamento científico e humanístico, devem orientar sua prática profissional para a função social que desempenham, para promover as condições de progresso econômico e bemestar da sociedade. (ALVES et al., 2016).

\subsection{Código de Ética Profissional}

O Código de Ética Profissional desempenha papel identificado da profissão, antes do exercício profissional contém os regulamentos para o desempenho em todo o trabalho que se faz e lida com a responsabilidade para com a sociedade em geral. $E$, no caso, específico dos contadores, nota-se que seu papel é muito importante, pois lidam com os detalhes financeiros íntimos de indivíduos e organizações. (ANTONOVZ et al., 2016).

Os códigos de ética são instrumentos normativos que estabelecem em seu escopo, princípios morais que os profissionais de contabilidade optam por cumprir para aprimorar sua profissão, manter a confiança e demonstrar honestidade e justiça perante a classe profissional e o público interessado pelos serviços contábeis. Por isso, as pessoas que ingressam nas organizações para atuarem como contadores precisam ciência de que é necessário atua e ao mesmo tempo proteger as credenciais para se apresentarem ao público com uma boa reputação da profissão. (ANTONOVZ et al., 2016).

"Os principais conceitos podem ser compreendidos a partir do artigo Art. 6음 do Decreto-Lei no 9.295/1946. (Decreto Federal, 1946), que relacionam a criação da ética e suas atribuições por lei." (JUSBRASIL, 2010, p.1) 
Infelizmente, nem todo mundo que trabalha na área contábil é confiável. Violações diárias da confiança pública e privada ocorrem e a solução percebível, é de fato a aplicação do Código de Ética Contábil, para que seja possível coibir a maioria dos dilemas éticos que envolvem os profissionais, porém nem sempre são favoráveis. (REDE JORNAL CONTABIL, 2019)

Segundo Cortina e Martinéz (2015), há cinco áreas que merecem a atenção de qualquer indivíduo que considere trabalhar na profissão contábil, sendo, importante destacar:

1. INDEPENDÊNCIA E OBJETIVIDADE: ética e independência andam de mãos dadas na profissão contábil. Trata-se de componente crítico da confiança na tomada de decisões e as recomendações imparciais que beneficiam o cliente. Conflitos de interesses, exigem exposição sob diretriz de independência; contudo, para que possa garantir as recomendações e não sujeitar-se a influência externa, é preciso entender que o julgamento profissional ocorrerá e, o contador poderá até perder o direito de exercer sua profissão.

2. INTEGRIDADE: demonstrar integridade significa ser direto e honesto em todos os negócios e relacionamentos profissionais. A manutenção da integridade exige que os contadores não se associem a informações que suspeitem serem materialmente falsas ou enganosas, que enganem por omissão ou que estejam ligadas a organizações criminosas.

3. CONFIDENCIALIDADE: divulgação de informações financeiras ou revelação de possível fusão por um profissional de contabilidade sem permissão, expressa e viola a confiança que é à base de um relacionamento profissional.

4. COMPETÊNCIA: à medida que a tecnologia, a legislação e as melhores práticas mudam, o contador deve permanecer atualizado. Para exercer o bom julgamento, o contador deve buscar do desenvolvimento e conhecimento para atuar sempre com eficiência e eficácia. Assim, praticar a virtude do zelo ou cuidado significa reconhecer seu nível de habilidade e não sugerir que possui experiência em área, na qual não possui. Consultar-se com outros profissionais é prática padrão que ajuda a unir a rede de profissionais e 
gerar respeito, porém se considerar desqualificado para o exercício profissional deve transferir os serviços a outro; mas, é claro, cabe sempre ao profissional, buscar treinamento e orientação adequada para desempenhar suas responsabilidades sempre que necessário.

5. COMPORTAMENTO PROFISSIONAL: a ética exige que os profissionais de contabilidade cumpram as leis e regulamentos que governam suas jurisdições e seus corpos de trabalho. Evitar ações que possam afetar negativamente à reputação da profissão é compromisso razoável que os parceiros de negócios e outros devem esperar.

Já em relação às possíveis infrações praticadas pelo profissional da contabilidade pode se listar algumas situações. Contudo, o CFC (2015), destaca que para cada uma dessas infrações, há enquadramento e penalidade aplicada de acordo com o fato ocorrido, conforme o Código de Ética Profissional:

- angariar clientes por meio de agenciador ou assinar documentos que não tenha sido elaborados pelo profissional;

- inexecução dos serviços contábeis para os quais foi expressamente contratado ou de serviços contábeis obrigatórios;

- adulteração ou manipulação fraudulenta na escrita ou em documentos, com o fim de favorecer a si mesmo ou a clientes;

- apropriação indébita e incapacidade técnica em relação a erros reiterados (precedida de processo de sindicância); aviltamento de honorários e concorrência desleal;

- retenção abusiva, danificação ou extravio de livros ou documentos contábeis, comprovadamente, entregue aos cuidados do contador.

As sanções éticas cometidas pelo contador são descritas pelo CFC (2019) no Código de Ética Profissional, sendo: advertência reservada; censura reservada e/ ou censura pública. Contudo, podem receber agravantes em suas penalidades, como também atenuantes, que dependerá da infração cometida pelo contador.

Deve-se observar também a necessidade de cumprir com as normas e regulamentos que envolvem a legislação da profissão, pois são complementos do Código de Ética Profissional. E, na existência de conflitos, deve-se observar sempre o Código de Ética, pois prevalece esta conduta como exigência para a profissão. (CFC, 2019). 


\section{CONSIDERAÇÕES FINAIS}

apresentar a importância da ética profissional por meio da análise do código ética contábil e mostrar sua influência na conduta e exercício do contador.

A ética é um conjunto de valores e princípios morais que orientam o comportamento humano na sociedade. Ele se concentra no equilíbrio e no bom funcionamento social. Dessa forma, ninguém pode ser prejudicado, pois cada sociedade e grupo social possuem seus próprios códigos de ética e padrões de comportamento.

Já a ética profissional objetiva e de independência importantes em valores éticos na profissão contábil os contadores devem permanecer livres de conflitos de interesse e outros relacionamentos questionáveis ao realizar serviços de contabilidade.

O devido cuidado é o valor ético que exige que os contadores observem todos os padrões técnicos ou éticos de contabilidade. Os contadores, geralmente, precisam revisar os princípios contábeis e aplicar sua estrutura às informações financeiras específicas de uma empresa. $O$ devido cuidado exige que os contadores exerçam competência, diligência, honestidade, responsabilidade, sigilo, zelo e entendimento adequado das informações financeiras.

Portanto pode- se concluir que o código de ética, contribui para o estabelecimento de normas e regras de conduta e poderá contribuir para o êxito do trabalho contábil. Desta forma, a formalização dessa conduta ética prescrita em código, poderá contribuir com o sucesso do contador e a sua ausência poderá conduzir a efetivação de sansões éticas (punições), seja por denuncia ou investigação do Conselho Federal de Contabilidade.

Assim o profissional contábil precisa ser verdadeiro ao oferecer serviços contábeis, bem como, ser preciso ao fornecer avaliação da saúde financeira aos usuários e interessados pela contabilidade ressaltando a importância do Código de Ética Profissional para garantir conduta ética e consistência a todos os profissionais; porém, na ausência, cabe denuncia ao CFC. 
Como sugestão, propõe-se a continuidade deste estudo, sendo efetuada a discussão de alguns pontos do código de ética, com mais precisão, já que neste estudo, não foi objeto.

\section{REFERÊNCIAS}

ALVES, F. J. S. et al. Um estudo empírico sobre a importância do código de ética profissional para o contabilista. Revista Cont. Fin., USP, São Paulo, Edição 30 Anos de Doutorado, p. 58 - 68, jun. 2016. Disponível em: <http://www.revistas.usp.br/rcf/article/view/34224>. Acesso em: 04 dez 2019

ANTONOVZ, T. et al. Atitudes éticas dos contadores: evidências recentes de uma pesquisa com alunos e profissionais contábeis sob perspectiva de gênero. RCO Revista de Contabilidade e Organizações - FEA-RP/USP, v. 4, n. 10, p. 89-105, set-dez 2016. Disponível em:< http://www.revistas.usp.br/rco/article/view/34778>. Acesso em: 04 dez 2019

ARANHA, M.L.A.; MARTINS, M.H.P. Filosofando - introdução à filosofia. 12. ed. São Paulo: Moderna. 2010.

CFC - Conselho Federal de Contabilidade. Código de ética profissional da contabilidade. 2019. Disponível em

< http://www.portaldecontabilidade.com.br/legislacao/cepc.htm>

Acesso em: 04 dez 2019

Abordagens éticas para o profissional contábil. Brasília: CFC, 2015. 90 p.

. Abordagens éticas para o profissional contábil. Brasília: CFC, 2015. 127 p

. Código de ética profissional da contabilidade. 2010. Disponível

em:<https://www.crcpr.org.br/new/content/download/codigoEtica.pdf>.

Acesso em: 04 dez 2019

CORTINA, A.; MARTINÉZ, E. Ética. 15. ed. Trad. LEITE, S.C. São Paulo: Loyola, 2015.

DANTAS, J. A.; DANTAS, J. M. M.; SILVA, C. A. T. O efeito de estímulos morais e éticos como resposta ao problema do risco moral: uma verificação experimental em grupos de estudantes de Ciências Contábeis. CONTEXTUS, Revista Contemporânea de Economia e Gestão, v. 10, n. 2, p. 36-47, jul./dez. 2014. Disponível em:<http://periodicos.ufc.br/contextus/article/view/32148>.

Acesso em: 04 dez 2019

FREITAS, A. C.; DIEHL, C. A.; MACAGNAN, C. B. Percepção Sobre Ética de Estudantes de Curso de Graduação em Ciências Contábeis. REPEC, Brasília, v. 5, n. 1, p. 21-49, abr, 2017. Disponível

em:<http://www.repec.org.br/repec/article/view/228>. Acesso em: 04 dez 2019 
LISBOA, L.P. Ética geral e profissional em contabilidade. São Paulo: Atlas, 1997.

LUSTOSA, P.R.B. et al. A moral do contador brasileiro: uma avaliação por meio da escala ética multidimensional. Revista Contabilidade Vista \& Revista, v. 23, n. 1, p. 15-45, jan./mar. 2016. Disponível em:< https://revistas.face.ufmg.br/index.php/contabilidadevistaerevista/article/view/1001 >. Acesso em: 04 dez 2019

MELO, L.A.S. Ética profissional contábil: aspectos e considerações dos alunos de ciências contábeis de uma universidade federal do interior de Minas Gerais. 14 Dez 2017. Disponível em: <https://repositorio.ufu.br/handle/123456789/20141>. Acesso em: 04 dez 2019

MORAES, M.C.C.; SILVA, A.M.C.; CARVALHO, F.A.A. O comportamento dos futuros contabilistas perante diferentes dilemas éticos. Pensar Contábil, Rio de Janeiro, v. 12, n. 48, p. 22 - 30, maio/ago. 2016. Disponível em:< http://www.atena.org.br/revista/ojs-2.2.3-

06/index.php/pensarcontabil/article/view/776>. Acesso em: 04 dez 2019

VALLS, Á.L.M. O que é ética. 7. ed. São Paulo: Brasiliense, 1993.

JUSBRASIL, 2010 Título da lei ou da matéria utilizada no trabalho.1949. Disponível em:< https://www.jusbrasil.com.br/topicos/12062139/artigo-6-do-decretolei-n-9295-de-27-de-maio-de-1946>. Acesso em: 19 nov. 2019.

REDE JORNAL CONTABIL, 2019 Artigo Decreto de lei 9.295/1946 utilizada no trabalho.

Disponível em:<https://www.jornalcontabil.com.br/conheca-as-penalidades-paraquem-descumprir-o-codigo-de-etica-da-contabilidade/>. Acesso em: 10 set. 2019. 